\title{
A educação musical no âmbito curricular das artes: um estudo exploratório com base na realidade Tocantinense*
}

\author{
Carlos Alberto Faísca Fernandes Gomes
}

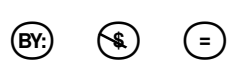

\section{Conteúdo}

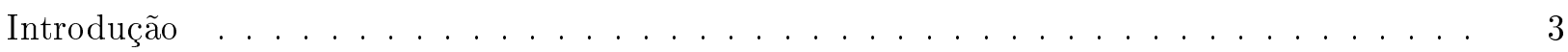

As determinações do Conselho Nacional de Educação . . . . . . . . . . . . . . 6

Os impactos da aprovação da Base Nacional Comum Curricular . . . . . . . . . . . . . . . 9

Análise da atual situação no Estado do Tocantins . . . . . . . . . . . . . . . . . . . 13

Considerações Finais . . . . . . . . . . . . . . . . . . . . . . 16

\section{Resumo}

Partindo de uma leitura influenciada pela experiência profissional do autor, este estudo tem como seu objetivo procurar conhecer a realidade vivida no Estado do Tocantins (Brasil) no que à educação musical diz respeito, tendo por base uma análise da sua rede estadual, e da rede municipal da sua capital estadual, de ensino, num estudo centrado em dois eixos distintos: o da evolução da grade curricular na rede estadual, entre 2013 e 2017, e a realidade vivida nas escolas da rede municipal de Palmas, Tocantins, no que à educação musical diz respeito.

Procurando nesta análise partir de uma visão nacional das diretrizes curriculares na área da educação musical, a metodologia de pesquisa utilizada é de carácter qualitativo, baseada na observação, na recolha documental, na análise de discurso, e na aplicação de um questionário aos professores de música em exercício de funções na cidade de Palmas, Tocantins, durante o segundo semestre de 2017.

No final conclui-se que, subsistindo na realidade brasileira uma disputa entre dois modelos de educação artística distintos - um caracterizado por uma abordagem integradora das diversas linguagens, e outro por uma visão mais autônoma que prevê espaços curriculares próprios para cada uma destas mesmas linguagens -, observa-se uma tendência de retrocesso, nomeadamente com a homologação da Base Nacional Comum Curricular $(B N C C)$, a uma visão mais integradora das linguagens artísticas, na esteira da Educação Artística prevista pela $L D B$ de 1971. Regista-se ainda o incumprimento estadual de normas e de diretrizes programáticas previstas para a educação musical a nível nacional.

Palavras Chave: Ensino de Artes, Educação Musical, Base Nacional Comum Curricular, Tocantins.

\footnotetext{
*Versão revista de artigo aceite para publicação, em julho de 2019, pela Revista Brasileira de Educação do Campo (ISSN 2525-4863), intitulado Perspectivas para uma educação musical no âmbito curricular das artes na educação básica: um estudo exploratório tendo por base a realidade Tocantinense.

${ }^{\dagger}$ Professor efetivo da Escola Artística de Música do Conservatório Nacional, em Lisboa, Portugal, em situação de licença sem vencimento, e atualmente professor substituto da Licenciatura em Educação do Campo, Códigos e Linguagens - Artes e Música, no Campus de Tocantinópolis da Universidade Federal do Tocantins, Brasil.
} 


\section{Abstract}

Based on a reading influenced by the professional experience of the author, this study aims to understand the reality experienced in the State of Tocantins (Brazil) with regard to music education, based on an analysis of its state education network, and the municipal education network of its state capital, in a study focused on two distinct axes: the evolution of the curriculum in the state network, between 2013 and 2017, and the reality experienced in the schools of the municipal network of Palmas, Tocantins, as far as music education is concerned.

Seeking in this analysis to start from a national view of the curriculum guidelines in the area of music education, the research methodology used is of a qualitative nature, based on observation, document collection, discourse analysis, and the application of a questionnaire to music teachers working in the city of Palmas, Tocantins, during the second half of 2017.

In the end, it is concluded that, persisting in the Brazilian reality a dispute between two distinct models of artistic education - one characterised by an integrative approach of different languages, and another by a more autonomous vision that provides curriculum spaces specific to each of these languages -, there is a tendency to regress, namely with the approval of the Common National Curriculum Base $(B N C C)$, to a more integrative vision of artistic languages, in the wake of the Artistic Education provided by $L D B$ of 1971 . It is also noted the state noncompliance with standards and programmatic guidelines for music education at national level.

Keywords: Arts Teaching, Music Education, Common National Curriculum Base, Tocantins. 


\section{Introdução}

Todo o conhecimento genuíno tem origem na experiência direta.

(Mao Tse-Tung)

Na esteira do empirismo britânico [35], podemos dizer que todo o nosso conhecimento é moldado e advém ao mesmo tempo da nossa própria experiência. É certo que, na história da epistemologia, ${ }^{1}$ nem sempre o conhecimento foi visto como sendo empírico, havendo aqueles que discordam de tal acepção, como é o caso de Renê Descartes (1596 - †1650), para quem o conhecimento é fruto da razão, fundamento basilar do seu método filosófico apelidado de dúvida cartesiana. É verdade que, em vez de se oporem completamente uma à outra, estas duas perspectivas epistemológicas acabam por se complementar entre si. Contudo, e ao contrario do que sucede com o racionalismo cartesiano, é característica do empirismo britânico que todo o conhecimento tenha por base uma experiência prévia. De facto, para os racionalistas, a fonte de todo o conhecimento é a razão e não a experiência, acreditando inclusive na existência de um conhecimento inato. Já para os empiristas, o conhecimento inato não existe, pois os mesmos entendem que sem experiência não pode haver saber.

Serve esta minha breve incursão pela epistemologia para circunscrever uma perspectiva analítica que irei aqui adotar, pois tal como os empiristas, creio que todo o conhecimento nasce, ou, pelo menos, é moldado pelas nossas próprias experiências, sendo a razão um mero instrumento analítico e de filtro sobre essas mesmas experiências. Para mim isso é relevante pois, sendo todo o conhecimento marcado, em maior ou menor grau, pelo nosso próprio subjetivismo - isto mesmo que não nos revejamos nas visões mais extremadas das teses epistemológicas pós-modernistas da era da pós-verdade ou da construção discursiva do real -, é inegável que as nossas experiências pessoais marcam sempre as nossas análises, mesmo aquelas que se querem de carácter científico. E acreditando não ser possível alcançar uma objetividade absoluta, opto por uma outra possibilidade que é a de sermos honestos com as nossas próprias subjetividades que moldam sempre e de alguma forma, mesmo que de maneira indelével, todo o conhecimento científico por nós produzido.

Esta noção, de que a subjetividade nunca deixa de estar presente na produção do conhecimento científico, tem tido impacto nas ciências sociais humanas, nomeadamente no âmbito da historiografia, onde,

ao construir a sua pesquisa, o historiador formula questões ao objeto que partem do seu presente. Contudo, as respostas não são um segredo guardadas a sete chaves [...]; elas encontram-se na construção discursiva feita pelo historiador. Suas respostas são balizadas por uma série de elementos criados para ajudar na abordagem dos problemas historiográficos. Diferentemente do que se acreditava [...], as convicções desempenham, no processo de produção do conhecimento, um papel muito mais decisivo. [9, pp. 18-19]

Ou seja, todo o conhecimento historiográfico depende em algum grau da nossa própria subjetividade, sendo que o que estes autores falam não deixa de ser igualmente verdadeiro em, pelo menos, algumas outras áreas do conhecimento científico, em especial no âmbito das ciências sociais e humanas, como é o caso das ciências da educação, âmbito no qual o presente estudo se insere.

\footnotetext{
${ }^{1}$ Uso aqui o conceito de epistemologia referindo-me ao estudo da origem, estrutura e validade do conhecimento, com especial enfoque no que apelidamos de conhecimento científico.
} 
Assim, a perspectiva que tenho construído, desde a minha chegada ao Brasil, sobre a educação musical brasileira, está indiscutivelmente marcada por mais de duas décadas e meia de atividade nesta área em Portugal, sobretudo no âmbito daquilo que por lá se designa de ensino especializado da música, ${ }^{2}$ atividade que desenvolvi quer como professor da área, quer como pesquisador. E, neste quesito, é preciso antes do mais assinalar as similitudes e as diferenças nas arquiteturas adotadas em ambos os sistemas educativos como forma de podermos estabelecer algumas referências comparativas entre estas duas realidades, ao mesmo tempo semelhantes e tão dispares entre si.

Primeiro uma questão de mera terminologia: o que em Portugal se designa de educação préescolar, de ensino básico, e de ensino secundário [21], no Brasil se designa respetivamente de pré-escola, ${ }^{3}$ de ensino fundamental e de ensino médio, o que engloba a chamada educação básica brasileira, de carácter obrigatório, universal e gratuito ${ }^{4}$ [24]. No entanto, e ao contrário do que sucede no caso português, onde há a previsão legal para a existência de uma estrutura de ensino especializado de música desde o chamado primeiro ciclo do ensino básico ${ }^{5}$ [4] - constituindo desta forma um sistema de ensino paralelo a uma formação de carácter mais genérico ao nível do chamado ensino básico e secundário -, na lei brasileira tal concepção é inexistente, havendo nesta uma visão mais monolítica de toda a educação básica, não se prevendo assim tais vias paralelas para a formação em determinadas áreas artísticas. Daí que se torne tão relevante toda a discussão em torno do alcance da dita educação artística prevista nos termos dos $\S \S 2 .{ }^{0}$ e $6 .^{0}$ do artigo 26. ${ }^{\circ}$ da Lei n. ${ }^{0}$ 9.394, de 20 de dezembro de 1996, que aprova as Diretrizes e Bases da Educação Nacional, em especial no que à educação musical diz respeito.

Na verdade, a referida disposição normativa somente estabelece, no que à educação artística diz respeito, o seguinte:

Art. 26. Os currículos da educação infantil, do ensino fundamental e do ensino médio devem ter base nacional comum, a ser complementada, em cada sistema de ensino e em cada estabelecimento escolar, por uma parte diversificada, exigida pelas características regionais e locais da sociedade, da cultura, da economia e dos educandos.

[...]

$\S 2 .^{0}$ O ensino da arte, especialmente em suas expressões regionais, constituirá componente curricular obrigatório da educação básica.

$[\ldots]$

$\S 6 .^{0}$ As artes visuais, a dança, a música e o teatro são as linguagens que constituirão o componente curricular de que trata o $\S 2 . \stackrel{0}{ }$ deste artigo.

$\left[24, \operatorname{art} .26 .^{\circ}, \S \S 2 .^{\circ}\right.$ e $\left.6 .^{\circ}\right]$

Note-se que sendo esta a atual redação dada ao caput e $\S \S 2 .^{0}$ e $6 .^{\circ}$ deste artigo $26 .^{0}$ da referida Lei de Diretrizes e Bases da Educação Nacional ( $L D B E N)$ de 1996, a mesma foi sendo sucessivamente alterada, sendo a atual versão o resultado de diversas alterações legislativas, entre as quais:

\footnotetext{
${ }^{2}$ Para mais informações sobre o referido sistema de ensino especializado, com especial enfoque na área da música, consultar, entre outros: [6, 7, 10, 11, 33].

${ }^{3}$ No Brasil a definição de educação infantil abrange as creches (até aos 3 anos de idade) e as pré-escolas (4 e 5 anos), enquanto que em Portugal a previsão legal se restringe somente à educação pré-escolar que se inicia aos 3 anos [21, art. 5.․․

${ }^{4}$ Em Portugal, o ensino obrigatório também corresponde atualmente àquilo que no Brasil se apelida de educação básica, só terminando com o final do ensino secundário [23, art. 2.ํ].

${ }^{5} \mathrm{O}$ primeiro ciclo do ensino básico corresponde no Brasil aos quatro primeiros anos do ensino fundamental.
} 
1. Lei n. ${ }^{0} 12.796$, de 4 de abril de 2013 , que introduz a redação atual do caput do referido artigo $26 \cdot \cdot^{0}[18]$;

2. Lei n. ${ }^{0} 13.415$, de 16 de fevereiro de 2017 , que mantém a determinação de que a educação artística, referida no $\S 2 . .^{\circ}$ do referido artigo $26 .^{\circ}$, se aplique a toda a educação básica [20], revogando a determinação de que a educação artística se restrinja somente à educação infantil e ao ensino fundamental conforme previsto na Medida Provisória n. ${ }^{0} 746$, de 22 de setembro de 2016 [26]; e

3. Lei n. ${ }^{\circ} 13.278$, de 2 de maio de 2016 , que veio a determinar, neste $\S 6 .^{\circ}$, que "as artes visuais, a dança, a música e o teatro são as linguagens que constituirão o componente curricular de que trata o $\S 2 .^{.}$" [19], sendo que já a Lei n..$^{0}$ 11.769, de 18 de agosto de 2008, tinha determinado que "a música deverá ser conteúdo obrigatório, mas não exclusivo, do componente curricular de que trata o mencionado $\S 2$. " [17].

Desta forma, constatamos que entre 2008 e 2017 houve a intenção, por parte do legislador brasileiro, de não só incluir especificamente, no currículo de Arte, quatro linguagens artísticas bem definidas $^{6}$ (artes visuais, dança, música e teatro), como o de manter a abrangência desta educação artística a toda a educação básica brasileira.

Contudo, apesar desta obrigatoriedade de inclusão, no currículo da educação básica, de uma formação e prática em quatro linguagens artísticas muito específicas (artes visuais, dança, música e teatro), durante o segundo semestre de 2017 constatei a existência de divergências entre as previsões acima referidas no âmbito da $L D B E N$ de 1996 e demais normativos, ${ }^{7}$ e a realidade observável na rede municipal de ensino da cidade de Palmas, Tocantins. É com base na pesquisa então efetuada, com ampla recolha documental da realidade vivida no referido sistema municipal de ensino, complementada com a experiência de lecionação de música numa escola de referência da referida rede municipal durante o ano de 2018, acrescida ainda de alguma outra pesquisa documental de âmbito estadual, que perspectivarei as atuais práticas ao nível da música tendo por referência a realidade existente na rede municipal da capital do Estado do Tocantins, passando ainda por algumas definições curriculares no âmbito da Secretaria Estadual de Educação do referido Estado, sempre enquadradas no âmbito das determinações vindas da esfera Federal, em especial da Base Nacional Comum Curricular $(B N C C)$ [28] recentemente aprovada e homologada.

É verdade que outras perspectivas de análise também se levantam, nomeadamente no âmbito teórico no que ao ensino da música diz respeito. E também aí constatamos existirem diferenças significativas ao nível das temáticas nacionais, quer quanto às pesquisas efetuadas, quer quanto às propostas pedagógicas apresentadas. Por exemplo, em Portugal, para além de uma ainda forte presença do modelo conservatorial ao nível do ensino especializado de música, nestas duas últimas décadas, os trabalhos de Edwin Gordon [12, 13, 14, 15] têm marcado, não só a emergência de linhas de pesquisa com base nos estudos e propostas do referido autor, como também algumas das práticas já hoje presentes nas ditas escolas de ensino especializado da música. Já no Brasil, Hans-Joachim Koellreutter parece ser um dos músicos e educadores musicais que fortemente marcam o discurso pedagógico no âmbito da educação musical [1]. Por outro lado, nos Estados Unidos, a educação musical é enquadrada no âmbito das inteligências $\operatorname{humanas}^{8}[8,13]$, sendo que uma das perspectivas aí trabalhadas é a relação entre as aprendizagens musicais e o desempenho acadêmico em outras áreas curriculares, variáveis que surgem

\footnotetext{
${ }^{6}$ Até então predominavam, de forma hegemônica, as artes visuais na esteira da Educação Artística prevista na Lei n. $\underline{0} 5.692$, de 11 de agosto de 1971 [22].

${ }^{7}$ Em especial da Resolução CNE/CEB n. ${ }^{0}$ 2, de 10 de maio de 2016 [32].

${ }^{8}$ Quer numa perspectiva de inteligências múltiplas [8], quer numa perspectiva psicométrica, passando pelo carácter desenvolvimental da aptidão musical [13, 34].
} 
como estando correlacionadas entre si de forma estatisticamente significativa $[2,16]{ }^{9}$

Porém, postas estas considerações, este estudo pretende discutir, não tanto os embasamentos teóricos, nem sempre visíveis nas práticas educativas existentes, mas sobretudo analisar as práticas tal como estas estão estruturadas na realidade vivenciada, pelo que dividirei esta minha análise, no que à componente curricular de Arte diz respeito e com especial enfoque para área da música, nos seguintes pontos de análise:

1. As atuais exigências regulamentares no âmbito da implementação do ensino da música nos currículos da educação básica brasileira;

2. Perspectivação histórica da componente curricular de Arte tendo por base a sua evolução conceptual no currículo da educação básica brasileira, desde a Lei de Diretrizes e Bases $(L D B)$ de 1971 [22], passando pela Lei de Diretrizes e Bases da Educação Nacional ( $L D$ $B E N)$ de 1996 [24], e culminando na Base Nacional Comum Curricular (BNCC) [28], analisando os impactos destas no que à componente curricular de Arte diz respeito;

3. Breve análise da atual situação existente no Estado do Tocantins tendo por base uma análise das evoluções curriculares ocorridas no sistema estadual de ensino (de 2013 a 2017) $[37,38,39]$ e da realidade vivida no âmbito da rede municipal de ensino de Palmas, Tocantins (anos de 2017 e de 2018).

E, apesar de fazer pontualmente referência a outras linguagens artísticas, é preciso ter presente que o escopo desta minha análise se foca no âmbito da educação musical ofertada no currículo escolar da educação básica brasileira no Estado do Tocantins, sendo esse o seu objeto e objetivo essencial de estudo. Também é preciso levar ainda em linha de conta que dadas as complexidades e diversidades que constituem o sistema educativo brasileiro como um todo, este estudo tem como sua limitação o material para o mesmo recolhido, havendo que proceder com algum cuidado quanto a eventuais extrapolações e generalizações no que à descrição das realidades analisadas diz respeito.

Por último, tendo como objetivo geral procurar conhecer a realidade vivida no Estado do Tocantins no que à educação musical diz respeito, e tendo por referência a rede estadual e a rede municipal da sua capital estadual, a metodologia de pesquisa utilizada foi de carácter essencialmente qualitativo, baseada na observação participante, na recolha documental, na análise de discurso, e na aplicação de um questionário aos professores de música em exercício de funções na cidade de Palmas, Tocantins, durante o segundo semestre de 2017. Este estudo se insere ainda numa modalidade de pesquisa exploratória, procurando o mesmo descrever e compreender uma realidade existente a nível local, enquadrando-a numa perspectiva mais geral e vasta, quer a nível nacional, quer tendo, por referência, outras realidades que constituem parte da subjetividade que não deixa de estar presente por detrás do referido estudo.

\section{As determinações do Conselho Nacional de Educação}

Após a alteração da redação dada ao $\S 6 .^{0}$ do artigo 26. $\cdot^{\circ}$ da $L D B E N$ de 1996 pela Lei n..$^{0}$ 11.769, de 18 de agosto de 2008 - passando-se a prever expressamente que a música passaria a ser conteúdo obrigatório, mas não exclusivo, da componente curricular de Arte -, e escassos dias após a adoção da atual redação do referido parágrafo através da alteração introduzida pela Lei n. ${ }^{0} 13.278$, de 2 de maio de 2016, a Comissão de Educação Básica do Conselho Nacional

\footnotetext{
${ }^{9}$ Isso significa que os alunos com melhor desempenho acadêmico são também aqueles que tendem a participar em algum tipo de programa de educação musical, mesmo que alguns desses estudos não nos permitam estabelecer uma relação de causa/efeito entre as variáveis consideradas visto serem de natureza correlacional e não de natureza longitudinal.
} 
de Educação, através da sua Resolução CNE/CEB n. ${ }^{0}$ 2, de 10 de maio de 2016, definiu um conjunto de diretrizes nacionais para a operacionalização do ensino de música no âmbito da educação básica. Note-se que sendo esta uma resolução com diretrizes nacionais, a mesma é de acatamento obrigatório, não só pela esfera Federal, como também pelos sistemas Estaduais e Municipais de ensino. E, apesar de irmos mais à frente constatar a existência de um possível retrocesso na realidade Tocantinense - nomeadamente por via da eliminação da disciplina de Educação Musical da parte diversificada da estrutura curricular da rede estadual de ensino sem que para isso tenha havido uma qualquer alteração do respetivo quadro normativo aplicável -, esta Resolução está ainda formalmente em vigor, ${ }^{10}$ constando entre os atos normativos, súmulas, pareceres e resoluções referenciados pelo Portal do Ministério da Educação. ${ }^{11}$

Esta Resolução [32] vai estabelecer um conjunto de deveres e obrigações para as escolas - que ficam desta forma obrigadas a incluir o ensino de música nos seus projetos político-pedagógicos -, as Secretarias Estaduais e Municipais de Educação - que, entre outras obrigações, deverão realizar concursos específicos para a contratação de licenciados em Música -, para as instituições formadoras de Educação Superior e de Educação Profissional - que entre outras medidas, deverão ampliar a oferta de licenciaturas em Música e incluir, nos cursos de pedagogia, o ensino de música visando a formação de professores para a educação infantil e para os anos iniciais do ensino fundamental -, não deixando ainda de atribuir competências específicas ao Ministério da Educação - que, entre outras obrigações, deverá apoiar técnica e financeiramente os diversos sistemas de ensino tendo em vista a inclusão do ensino de música nas escolas públicas de educação básica -, bem como aos Conselhos Estaduais e Municipais de Educação.

Esta Resolução contém um conjunto de determinações que desde a sua entrada em vigor, ocorrida na data de sua publicação no Diário Oficial da União, ${ }^{12}$ vinculam os vários atores educativos a prosseguir no sentido de implementarem uma política ativa de promoção do ensino de música no âmbito da educação básica brasileira. Dada a sua importância, elenco seguidamente o conjunto de obrigações previstas na referida Resolução:

1. No âmbito das escolas de educação básica:

(a) Incluir o ensino de música nos seus projetos político-pedagógicos como conteúdo curricular obrigatório;

(b) Criar ou adequar tempos e espaços para o ensino de música;

(c) Realizar atividades musicais para todos os seus estudantes;

(d) Organizar seus quadros de profissionais da educação com professores licenciados em Música;

(e) Promover a formação continuada de seus professores;

(f) Estabelecer parcerias com instituições e organizações formadoras e associativas ligadas à música;

(g) Desenvolver projetos e ações como complemento das atividades letivas.

2. No âmbito das Secretarias Estaduais e Municipais de Educação:

(a) Identificar, em seus quadros de magistério e de servidores, profissionais vocacionados que possam colaborar com o ensino de música nas escolas;

(b) Promover cursos de formação continuada sobre o ensino de música;

\footnotetext{
10 Vigência confirmada em janeiro de 2020.

11 Cf. http://portal.mec.gov.br/component/content/article?id=34011.

12 A referida Resolução foi publicada no Diário Oficial da União, n. ${ }^{0}$ 89, de 11 de maio de 2016, seção 1 , à página 421.
} 
(c) Apoiar a formação dos professores e dos demais profissionais da educação em cursos de segunda licenciatura em Música;

(d) Criar bancos de dados sobre práticas de ensino de música, divulgando-os;

(e) Promover a elaboração, a publicação e a distribuição de materiais didáticos adequados ao ensino de música nas escolas;

(f) Organizar redes de instituições ligadas à música com vista ao intercâmbio de experiências docentes e de projetos musicais;

(g) Realizar concursos específicos para a contratação de licenciados em Música;

(h) Cuidar do planejamento arquitetônico das escolas de modo que disponham de instalações adequadas ao ensino de música;

(i) Viabilizar a criação de Escolas de Música, ou de instituições similares, que promovam a formação profissional em Música.

3. Já quanto às instituições formadoras de Ensino Superior e de Formação Profissional, compete às mesmas:

(a) Ampliar a oferta de cursos de licenciatura em Música;

(b) Ofertar cursos de segunda licenciatura em Música;

(c) Incluir nos currículos dos cursos de Pedagogia o ensino de música;

(d) Implementar a oferta de cursos técnicos de nível médio na área da Música;

(e) Ofertar cursos de formação continuada;

(f) Orientar para que o estágio supervisionado e a prática de ensino dos cursos de graduação em Música tenham parte de sua carga horária dedicada ao ensino de música nas escolas de educação básica;

(g) Estabelecer parcerias nacionais e internacionais de ensino, pesquisa e extensão em Música.

4. Relativamente ao Ministério da Educação, ao mesmo competirá:

(a) Apoiar técnica e financeiramente os sistemas de ensino;

(b) Estimular a oferta de cursos de licenciatura em Música;

(c) Estimular a oferta de cursos de formação inicial e continuada na área do ensino de música;

(d) Incentivar a realização de estudos e pesquisas sobre as temáticas da música e do ensino de música na educação básica;

(e) Estabelecer parcerias interinstitucionais;

(f) Zelar pela presença de indicadores atinentes ao ensino de música, nomeadamente ao nível dos recursos humanos, materiais, e de avaliação da educação básica.

5. Por último, quanto aos Conselhos Estaduais e Municipais de Educação, os mesmos serão responsáveis por:

(a) Definir normas complementares a estas Diretrizes; ${ }^{13}$

\footnotetext{
${ }^{13}$ Mas se tratando de normas complementares submetidas juridicamente a esta Resolução, as mesmas não a deverão subverter, quer no seu espírito, quer na sua letra. É que apesar de no Brasil não se prever uma "superioridade da lei federal em face da lei estadual ou municipal" [25], o princípio doutrinal conhecido como a pirâmide de Kelsen aponta para o facto de que não poderão deixar de ser aqui atendidas, pelos Conselhos Estaduais e Municipais de Educação, as normas estabelecidas nesta Resolução visto que aos mesmos compete o estabelecimento de normas complementares às Diretrizes aqui definidas.
} 
(b) Realizar o acompanhamento dos Planos de Educação quanto à avaliação da implementação das políticas públicas concernentes ao ensino de música na educação básica.

Sem muito esforço, somente com algum conhecimento das práticas existentes no terreno, não nos é muito difícil constatar que no Tocantins muitas destas determinações ainda carecem de efetivo cumprimento, tendo havido inclusive alguns retrocessos, como foi a retirada da disciplina de Educação Musical das novas estruturas curriculares da rede estadual de ensino que vigoram desde 2017 - diluindo-a nas disciplinas de Arte e de Produção e Expressão Artística -, ou mesmo uma sensível mudança das políticas nesta área por parte da Prefeitura Municipal de Palmas, Tocantins, ao não prever a contratação de professores devidamente habilitados nesta área no processo de contratação levado a cabo no ano escolar de 2019. ${ }^{14}$

\section{Os impactos da aprovação da Base Nacional Comum Curricular}

No final de 2018 assistimos à aprovação e homologação final da chamada Base Nacional Comum Curricular $(B N C C)$ [28] para a educação básica. Durante o referido processo de discussão e adaptação para o Estado do Tocantins, ocorrido ainda durante o ano de 2018, já me tinha posicionado quanto ao que julgo serem algumas deficiências relativas à educação musical no âmbito da referida componente curricular de Arte aí prevista. Para começar, a referida $B N C C$, no que diz respeito à Arte, parece-me manter latente um conflito entre duas concepções distintas de educação artística: a prevista pela $L D B$ de 1971 [22] e, a outra, a que pode ser aferida da atual versão do $\S 6 .^{\circ}$ do artigo $26 .^{\circ}$ da $L D B E N$ de 1996 [24]. De facto, na $L D B$ de 1971 a concepção de educação artística é entendida como sendo caracterizada por uma perspectiva integradora das diversas linguagens artísticas, não havendo uma referência explícita a quais destas deverão ser abordadas no seu âmbito [22, art. 7.․]. Tal facto possibilitou a que na prática a referida Educação Artística se tornasse quase que num sinônimo de artes visuais, acabando por retirar espaço às restantes linguagens artísticas. ${ }^{15}$ Em sentido diverso, a $L D B E N$ de 1996, na redação atualmente adotada no $\S 6 .^{\circ}$ do seu artigo $26 .^{\circ}$ - primeiramente pela Lei n. ${ }^{0} 11.769$ [17] e posteriormente pela Lei n. ${ }^{0} 13.278$ [19] -, passou a conceber um espaço curricular distinto que deverá ser ocupado, dentro da componente curricular de Arte, por cada uma de quatro linguagens artísticas expressamente aí mencionadas: artes visuais, dança, música e teatro.

De facto, passamos de uma concepção integradora das diversas linguagens artísticas para uma visão curricular que as distingue, a caminho de uma perspectiva disciplinar autônoma destas, dadas as especificidades inerentes a cada uma das referidas linguagens. E tanto assim é que o referido retrocesso conceptual, num retorno a uma visão integrada das diversas linguagens artísticas, pode ser entendido em dois momentos distintos na referida $B N C C$, nomeadamente quando:

1. Se considera que cada uma das quatro linguagens atualmente previstas no $\S 6 .{ }^{0}$ do artigo 26. ํ da $L D B E N$ de 1996 constitui uma unidade temática de Arte e não uma possível

\footnotetext{
14 A Portaria GAB/SEMED n. ${ }^{0}$ 16, de 16 de janeiro de 2019, não prevê a contratação de professores devidamente habilitados nas diversas áreas artísticas [29], constituindo tal facto um retrocesso face às práticas adotadas na gestão municipal anterior no que à área curricular de Arte diz respeito.

15 Apesar das licenciaturas em Educação Artística então preverem a possibilidade de habilitação em outras linguagens para além das artes visuais, na prática, por razões diversas, a mesma se tornou praticamente sinônimo de artes visuais, havendo uma clara perda de espaço para as restantes linguagens artísticas, fenômeno este que não é exclusivo da realidade brasileira.
} 
unidade disciplinar autônoma; ${ }^{16}$

2. Se prevê algo próximo a uma quinta linguagem artística, não mencionada na atual redação do $§ 6 .^{\circ}$ do referido artigo $26 .^{\circ}$ da $L D B E N$ de 1996 , designada de artes integradas, a qual "explora as relações e articulações entre as diferentes linguagens e suas práticas, inclusive aquelas possibilitadas pelo uso das novas tecnologias de informação e comunicação" [28, p. 197], o que não deixa de ser uma perspectiva integrada e não autônoma das referidas linguagens artísticas, com claros riscos para a perda de suas identidades próprias. ${ }^{17}$

Ou seja, apesar da redação atual da $L D B E N$ de 1996 não impor uma concepção disciplinarmente autônoma para as artes visuais, a dança, a música e o teatro, tal entendimento não deixou provavelmente de estar subjacente à atual redação do $\S 6 .^{0}$ do seu artigo $26 .^{0}$, algo que nos é indiciado não só pelo teor da já mencionada Resolução CNE/CEB n. ${ }^{0} 2 / 2016$, como pelo próprio entendimento dado pelas Secretarias de Educação que vinham incluindo disciplinas distintas no âmbito das artes ${ }^{18}$ nas suas estruturas curriculares para a educação básica com vista a dar cabal cumprimento à referida disposição normativa constante da $L D B E N$ de 1996. E sem que houvesse uma alteração do referido quadro normativo, a $B N C C$ veio dar um possível espaço para que as diversas linguagens artísticas aí previstas possam voltar a ser encaradas como meras unidades temáticas e não mais como eventuais disciplinas autônomas, havendo desta forma o risco de um empobrecimento dos conteúdos curriculares ministrados no âmbito da componente curricular de Arte, nomeadamente por ser extremamente improvável encontrar algum professor igualmente proficiente nas referidas quatro linguagens artísticas, razão aliás que terá estado na base da transformação da dita Educação Artística prevista na LDB de 1971 num quase sinônimo de artes visuais, uma vez que a grande maioria dos professores da referida área curricular tendia a possuir habilitação em artes visuais e não nas demais linguagens artísticas.

Um outro problema que podemos encontrar quanto à Música na referida $B N C C$, no que ao ensino fundamental diz respeito, ${ }^{19}$ está na deficiente definição das habilidades aí previstas, havendo, para além de algumas outras questões, uma aparente falta de perspectivação teórica dos referidos objetos de conhecimentos e respetivas habilidades no âmbito da pedagogia musical. De facto, observemos a definição dos objetos de conhecimento e das habilidades previstas para a mencionada unidade temática de Música da componente curricular de Arte:

\begin{tabular}{|c|c|l|}
\hline Anos & Objetos de Conhecimento & Habilidades \\
\hline \hline & & (EF15AR13) Identificar e apreciar criticamente diversas for- \\
& Contextos e práticas & $\begin{array}{l}\text { mas e gêneros de expressão musical, reconhecendo e analisando } \\
\text { os e as funções da música em diversos contextos de cir- }\end{array}$ \\
& & culação, em especial, aqueles da vida cotidiana. \\
\hline
\end{tabular}

${ }^{16}$ É difícil conceber a existência de um professor polivalente e igualmente especialista nas quatro linguagens artísticas previstas no $\S 6 .^{\circ}$ do artigo 26. ํㅡㄹ da $L D B E N$ de 1996. Tanto assim é que a citada Resolução CNE/CEB n..$^{0}$ 2/2016 prevê especificamente a necessidade de contratação de professores licenciados em Música [32, art. $\left.1 .^{o}, \S 2 .^{\circ}, \mathrm{VII}\right]$, o que analogamente deveria ocorrer com as restantes linguagens artísticas (artes visuais, dança e teatro).

${ }^{17}$ E mesmo se defendendo uma perspectiva interdisciplinar, isso não deixa de já ocorrer no âmbito do estudo autônomo de cada uma das referidas linguagens artísticas. Por exemplo, dificilmente há dança sem música, tal como a ópera não deixa de ser considerada como sendo um gênero eminentemente musical apesar de esta agregar à música pelo menos outras duas linguagens artísticas, como é o caso da arte de representar (teatro) e da cenografia (artes visuais).

18 No âmbito da rede municipal de ensino de Palmas, Tocantins, houve, no período a que se reporta o presente estudo (2017 e 2018), a previsão de disciplinas autônomas de Música, Dança e Teatro englobadas na parte diversificada da estrutura curricular do ensino fundamental.

19 A referida $B N C C$ não define habilidades que se possam considerar como sendo efetivamente do âmbito musical para o ensino médio - o que consta no documento, na área das linguagens, é realmente muito escasso -, pelo que a presente análise será efetuada somente sobre o ensino fundamental. 


\begin{tabular}{|c|c|c|}
\hline $1^{\mathrm{O}} ; 2^{\mathrm{O}} ; 3^{\mathrm{O}} ; 4^{\mathrm{O}} ; 5^{\mathrm{O}}$ & Elementos da linguagem & $\begin{array}{l}\text { (EF15AR14) Perceber e explorar os elementos constitutivos } \\
\text { da música (altura, intensidade, timbre, melodia, ritmo etc.), } \\
\text { por meio de jogos, brincadeiras, canções e práticas diversas de } \\
\text { composição/criação, execução e apreciação musical. }\end{array}$ \\
\hline $1^{\mathrm{O}} ; 2^{\mathrm{O}} ; 3^{\mathrm{O}} ; 4^{\mathrm{O}} ; 5^{\mathrm{O}}$ & Materialidades & $\begin{array}{l}\text { (EF15AR15) Explorar fontes sonoras diversas, como as exis- } \\
\text { tentes no próprio corpo (palmas, voz, percussão corporal), na } \\
\text { natureza e em objetos cotidianos, reconhecendo os elementos } \\
\text { constitutivos da música e as características de instrumentos } \\
\text { musicais variados. }\end{array}$ \\
\hline $1^{\mathrm{O}} ; 2^{\mathrm{O}} ; 3^{\mathrm{O}} ; 4^{\mathrm{O}} ; 5^{\mathrm{O}}$ & Notação e registro musical & $\begin{array}{l}\text { (EF15AR16) Explorar diferentes formas de registro musical } \\
\text { não convencional (representação gráfica de sons, partituras } \\
\text { criativas etc.), bem como procedimentos e técnicas de regis- } \\
\text { tro em áudio e audiovisual, e reconhecer a notação musical } \\
\text { convencional. }\end{array}$ \\
\hline $1^{\mathrm{O}} ; 2^{\mathrm{O}} ; 3^{\mathrm{O}} ; 4^{\mathrm{O}} ; 5^{\mathrm{O}}$ & Processos de criação & $\begin{array}{l}\text { (EF15AR17) Experimentar improvisações, composições e so- } \\
\text { norização de histórias, entre outros, utilizando vozes, sons cor- } \\
\text { porais e/ou instrumentos musicais convencionais ou não con- } \\
\text { vencionais, de modo individual, coletivo e colaborativo. }\end{array}$ \\
\hline $6^{\underline{Q}} ; 7^{0} ; 8^{0} ; 9^{\underline{Q}}$ & Contextos e práticas & $\begin{array}{l}\text { (EF69AR16) Analisar criticamente, por meio da apreciação } \\
\text { musical, usos e funções da música em seus contextos de pro- } \\
\text { dução e circulação, relacionando as práticas musicais às dife- } \\
\text { rentes dimensões da vida social, cultural, política, histórica, } \\
\text { econômica, estética e ética }\end{array}$ \\
\hline $6^{\mathrm{o}} ; 7^{\mathrm{o}} ; 8^{\mathrm{o}} ; 9^{\underline{0}}$ & Contextos e práticas & $\begin{array}{l}\text { (EF69AR17) Explorar e analisar, criticamente, diferentes } \\
\text { meios e equipamentos culturais de circulação da música e do } \\
\text { conhecimento musical. }\end{array}$ \\
\hline $6^{\underline{O}} ; 7^{\underline{0}} ; 8^{\underline{0}} ; 9^{\underline{Q}}$ & Contextos e práticas & $\begin{array}{l}\text { (EF69AR18) Reconhecer e apreciar o papel de músicos e gru- } \\
\text { pos de música brasileiros e estrangeiros que contribuíram para } \\
\text { o desenvolvimento de formas e gêneros musicais. }\end{array}$ \\
\hline $6^{\underline{Q}} ; 7^{\mathrm{Q}} ; 8^{\mathrm{O}} ; 9^{\mathrm{Q}}$ & Contextos e práticas & $\begin{array}{l}\text { (EF69AR19) Identificar e analisar diferentes estilos musicais, } \\
\text { contextualizando-os no tempo e no espaço, de modo a apri- } \\
\text { morar a capacidade de apreciação da estética musical. }\end{array}$ \\
\hline $6^{\underline{O}} ; 7^{\mathrm{O}} ; 8^{\mathrm{O}} ; 9^{\underline{Q}}$ & Elementos da linguagem & $\begin{array}{l}\text { (EF69AR20) Explorar e analisar elementos constitutivos da } \\
\text { música (altura, intensidade, timbre, melodia, ritmo etc.), por } \\
\text { meio de recursos tecnológicos (games e plataformas digitais), } \\
\text { jogos, canções e práticas diversas de composição/criação, exe- } \\
\text { cução e apreciação musicais. }\end{array}$ \\
\hline $6^{\mathrm{O}} ; 7^{\mathrm{O}} ; 8^{\mathrm{O}} ; 9^{\mathrm{O}}$ & Materialidades & $\begin{array}{l}\text { (EF69AR21) Explorar e analisar fontes e materiais sonoros em } \\
\text { práticas de composição/criação, execução e apreciação musi- } \\
\text { cal, reconhecendo timbres e características de instrumentos } \\
\text { musicais diversos. }\end{array}$ \\
\hline $6^{\underline{O}} ; 7^{0} ; 8^{0} ; 9^{\underline{O}}$ & Notação e registro musical & $\begin{array}{l}\text { (EF69AR22) Explorar e identificar diferentes formas de regis- } \\
\text { tro musical (notação musical tradicional, partituras criativas } \\
\text { e procedimentos da música contemporânea), bem como pro- } \\
\text { cedimentos e técnicas de registro em áudio e audiovisual. }\end{array}$ \\
\hline
\end{tabular}




\begin{tabular}{|c|l|l|}
\hline \multirow{2}{*}{$6^{\mathrm{o}} ; 7^{\mathrm{O}} ; 8^{\mathrm{o}} ; 9^{\mathrm{O}}$} & $\begin{array}{l}\text { (EF69AR23) Explorar e criar improvisações, composições, ar- } \\
\text { ranjos, jingles, trilhas sonoras, entre outros, utilizando vozes, } \\
\text { sons corporais e/ou instrumentos acústicos ou eletrônicos, con- } \\
\text { vencionais ou não convencionais, expressando ideias musicais } \\
\text { de maneira individual, coletiva e colaborativa. }\end{array}$ \\
\hline
\end{tabular}

Para além da falta de uma definição de habilidades que coerentemente possam ser perspectivadas em alguma das diferentes correntes teóricas no âmbito da pedagogia musical [3, 12, 14, 15, $27,40],{ }^{20}$ encontramos alguns problemas conceptuais na sua definição, entre os quais:

1. O colocar, no mesmo plano conceptual, os conceitos de altura, intensidade, timbre, melodia, e ritmo, quando na verdade estes pertencem a duas ordens conceptuais distintas entre si: ${ }^{21}$

(a) Por um lado, conceitos de ordem primária que se referem à característica individual de cada som considerado de forma isolada, normalmente designadas de parâmetros do som, e referentes à sua altura, duração, timbre e intensidade;

(b) Por outro lado, conceitos de ordem secundária que se referem ao conjunto de dois ou mais sons sucessivos: melodia e ritmo. De facto, só há melodia quando ouvimos sequencialmente dois ou mais sons de altura e duração igual ou diversa entre si, tal como só há ritmo quando ouvimos sequencialmente dois ou mais sons de duração igual ou diversa entre si. ${ }^{22}$

2. A ênfase dada, em algumas destas habilidades, a temáticas que tratam questões em torno das práticas musicais em vez de visarem o domínio específico de competências técnicomusicais propriamente ditas (como a formação de ouvido, a leitura musical e a execução instrumental), se afastando desta forma das concepções teóricas existentes ao nível da pedagogia musical. ${ }^{23}$

De uma maneira geral, dificilmente esta definição de habilidades pode ser considerada como sendo o reflexo claro e objetivo de alguma das diversas visões teóricas existentes ao nível da pedagogia musical, ${ }^{24}$ sendo neste aspecto um retrocesso se daqui houver uma visão redutora na sua aplicação, acabando com algumas das práticas e experimentações que se vinham até aqui fazendo no âmbito da educação musical, como seja a previsão de uma disciplina de Educação Musical integrada na parte diversificada da estrutura curricular da educação básica, a par de todo um investimento efetuado ao nível de projetos musicais levados à prática, por exemplo, na rede municipal de ensino de Palmas, Tocantins.

\footnotetext{
${ }^{20}$ Conforme bibliografia citada, aqui faço referência às perspectivas teóricas para a educação musical, propostas, entre outros, por Émile Jacques-Dalcroze, Zoltán Kodály, Edgar Willems, Carl Orff, Maurice Martenot, Shinichi Suzuki, Gertrud Meyer-Denkmann, John Paynter, Raymond Murray Schafer, Jos Wuytack, Keith Swanwick, e Edwin Gordon.

21 A este propósito ver as habilidades EF15AR14 e EF69AR20.

${ }^{22}$ Toda a melodia possui ritmo, mas nem todo o ritmo possui melodia, pois o mesmo pode ser resultante de sons de altura indefinida.

23 A este propósito ver as habilidades EF15AR13, EF69AR16, EF69AR17, e EF69AR18.

${ }^{24}$ A este propósito, podemos ainda referir as seis dimensões que são mencionadas na $B N C C$ como caracterizando a experiência artística - a criação, a crítica, a estesia, a expressão, a fruição, e a reflexão [28, pp. 194-195] -, as quais não só valorizam aspectos não mencionados nas referidas correntes da pedagogia musical, como deixam de fora dimensões consideradas fundamentais à prática musical como é o caso da performance. Por exemplo, Keith Swanwick, ao propor o seu modelo $\mathrm{C}(\mathrm{L}) \mathrm{A}(\mathrm{S}) \mathrm{P}$, se refere expressa e exclusivamente às dimensões da criação musical - i.e., da composição -, do estudo da literatura musical - i.e., do reportório musical -, da apreciação musical, da técnica, e da performance, os quais são análogos na sua estruturação, mas distintos no seu conteúdo, quando comparados com a abordagem adotada pela $B N C C$ no âmbito das artes.
} 
E não deixa de ser curioso constatar que, apesar das suas diferenças de pormenor, a assertividade no âmbito das respetivas concepções teóricas, ou da falta das mesmas, por detrás das diretrizes para o ensino de música, constantes da referida $B N C C$, não são substantivamente tão dispares quando comparadas com os referenciais curriculares estabelecidos em 2009 para o ensino fundamental no Estado do Tocantins [36], mesmo que agora haja uma definição mais pormenorizada, apesar de questionável, das habilidades a serem alcançadas no âmbito da música. $^{25}$ Por isso, esta não parece poder ser a razão por detrás do desaparecimento da disciplina de Educação Musical na estrutura curricular estabelecida a partir do ano escolar de 2017 para a rede estadual de ensino do Tocantins [30, 31], tal como a mesma não decorreu de uma qualquer outra alteração ao nível do respetivo quadro normativo para a educação básica, visto este não ter sofrido qualquer alteração, à excepção da aprovação e homologação da já mencionada $B N C C$.

\section{Análise da atual situação no Estado do Tocantins}

Procedendo à análise das estruturas curriculares aprovadas para o Estado do Tocantins, ${ }^{26}$ com vigência respetivamente a partir dos anos escolares de 2013 e de 2017, verificamos que a Música, sob a forma de uma disciplina de Educação Musical colocada na parte diversificada do currículo, teve uma existência efêmera, tendo estado somente presente nas estruturas curriculares, aprovadas para o ensino fundamental em regime de Tempo Integral, entre os anos escolares de 2013 e 2016, pela Resolução CEE/TO n. ${ }^{-}$234, de 19 de dezembro de 2012, sendo que, a partir do ano escolar de 2017, deixa de haver tal previsão conforme o disposto na Resolução CEE/TO n. ${ }^{\circ}$ 160, de 19 de dezembro de 2016.

De facto, não só nas estruturas curriculares para o ensino médio, apesar de se encontrar prevista a disciplina de Arte no âmbito da área do conhecimento das linguagens, a disciplina de Educação Musical nunca teve uma qualquer existência na parte diversificada do currículo, ${ }^{27}$ como no ensino fundamental a dita disciplina de Educação Musical só teve uma existência efêmera entre os anos escolares de 2013 e 2016 e somente em escolas funcionando em regime de Tempo Integral. Por essa razão, na Tabela 2 na página seguinte, apenas faço referência ao ensino fundamental - pois, no ensino médio, a disciplina de Educação Musical nunca existiu nas estruturas curriculares em análise -, sendo que a disciplina de Arte se encontra sempre presente na área das linguagens em todas as estruturas curriculares analisadas, mesmo que a partir do ano escolar de 2017 a sua carga horária semanal tenha sido alargada, em alguns casos, para as duas horas semanais, introduzindo-se ainda, nas escolas em regime de Tempo Integral, a disciplina de Produção e Expressão Artística no âmbito da parte diversificada do currículo e em substituição das disciplinas de Educação Musical, ${ }^{28}$ Dança e Teatro, as quais estavam também na referida parte diversificada do currículo.

Da análise comparativa destas estruturas curriculares com vigência respectiva entre 2013 e 2016, e a partir de 2017, no que às artes diz respeito, verificamos o desaparecimento das disciplinas autônomas para as áreas da dança, da música e do teatro, sem que isso contudo

\footnotetext{
25 A este propósito, comparar os quadros referentes às habilidades definidas no âmbito da componente curricular de Arte nos dois documentos em causa: [36, pp. 47-57] e [28, pp. 200-203 e 206-211].

${ }^{26}$ Ver estruturas curriculares aprovadas pelas Resoluções CEE/TO n. $\stackrel{0}{2} 234$, de 19 de dezembro de 2012 , n. $\underline{0}$ 160, de 19 de dezembro de 2016, e n. ${ }^{0}$ 11, de 14 de fevereiro de 2017 [37, 38, 39].

${ }^{27}$ Mas nas observações anexas às referidas estruturas curriculares do ensino médio, consta sistematicamente a indicação de que a Música deve ser conteúdo obrigatório a ser trabalhado na componente curricular de Arte.

28 É curioso constatar que nas Escolas do Campo em regime de Tempo Integral, nas estruturas curriculares em vigor entre 2013 e 2016, apesar de na parte diversificada do currículo encontrarmos a disciplina de Educação Musical, as disciplinas de Dança e de Teatro só têm presença nas escolas urbanas a funcionarem em regime de Tempo Integral.
} 
Tab. 2: A evolução da componente curricular de Arte nas escolas estaduais do Tocantins.

\begin{tabular}{|c|c|c|c|}
\hline \multicolumn{2}{|c|}{ Curso (Ensino Fundamental) } & \multirow{2}{*}{$\begin{array}{c}\text { Vigência a partir de } 2013 \\
\text { Arte }(1 \mathrm{~h})+\text { Dança }(1 \mathrm{~h})+\text { Educação } \\
\text { Musical }(2 \mathrm{~h})+\text { Teatro }(2 \mathrm{~h})\end{array}$} & \multirow{2}{*}{$\begin{array}{c}\text { Vigência a partir de } \mathbf{2 0 1 7} \\
\text { Arte }(2 \mathrm{~h})+\text { Produção e Expressão } \\
\text { Artística }(2 \mathrm{~h})\end{array}$} \\
\hline \multirow{6}{*}{ 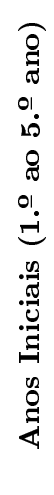 } & Tempo Integral & & \\
\hline & $\begin{array}{l}\text { Tempo Integral - Escola } \\
\text { do Campo }\end{array}$ & $\operatorname{Arte}(1 \mathrm{~h})+$ Educação Musical (2h) & $\begin{array}{c}\text { Arte }(2 \mathrm{~h})+\text { Produção e Expressão } \\
\text { Artística }(2 \mathrm{~h})\end{array}$ \\
\hline & Tempo Parcial & Arte $(1 \mathrm{~h})$ & Arte $(1 \mathrm{~h})$ \\
\hline & $\begin{array}{l}\text { Tempo Parcial - Escola do } \\
\text { Campo }\end{array}$ & - & Arte $(2 \mathrm{~h})$ \\
\hline & $\begin{array}{c}\text { Tempo Parcial - Escola } \\
\text { Quilombola }\end{array}$ & - & Arte $(1 \mathrm{~h})$ \\
\hline & Tempo Parcial - Indígena & Arte (1h) & Arte (1h) \\
\hline \multirow{6}{*}{ 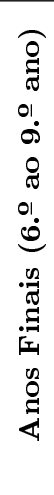 } & Tempo Integral & $\begin{array}{c}\text { Arte }(1 \mathrm{~h})+\text { Dança }(1 \mathrm{~h})+\text { Educação } \\
\text { Musical }(2 \mathrm{~h})+\text { Teatro }(1 \mathrm{~h})\end{array}$ & $\begin{array}{c}\text { Arte }(2 \mathrm{~h})+\text { Produção e Expressão } \\
\text { Artística }(2 \mathrm{~h})\end{array}$ \\
\hline & $\begin{array}{l}\text { Tempo Integral - Escola } \\
\text { do Campo }\end{array}$ & Arte (1h) + Educação Musical (2h) & $\begin{array}{c}\text { Arte }(2 \mathrm{~h})+\text { Produção e Expressão } \\
\text { Artística }(2 \mathrm{~h})\end{array}$ \\
\hline & Tempo Parcial & Arte $(1 \mathrm{~h})$ & Arte $(1 \mathrm{~h})$ \\
\hline & $\begin{array}{c}\text { Tempo Parcial - Escola do } \\
\text { Campo }\end{array}$ & - & Arte (2h) [REVOGADO] \\
\hline & $\begin{array}{c}\text { Tempo Parcial - Escola } \\
\text { Quilombola }\end{array}$ & - & Arte (2h) [REVOGADO] \\
\hline & Tempo Parcial - Indígena & Arte (1h) & Arte (1h) [REVOGADO] \\
\hline
\end{tabular}

nos permita afirmar que tal determinação implique no desaparecimento por completo das mesmas - no caso que nos concerne da música - do currículo das referidas escolas estaduais, isto até porque, nas observações anexas às estruturas curriculares aprovadas pela já mencionada Resolução CEE/TO n. ${ }^{0} 160$ existe sistematicamente a determinação de que "a Música (Educação Musical) deverá ser conteúdo obrigatório, mas não exclusivo [...] [devendo o mesmo] ser trabalhado na componente curricular de Arte." 29 No entanto, não só poderá isso determinar que a componente curricular de Música poderá deixar de ser ministrada por docentes com a devida capacitação na área - inclusive, indo em sentido oposto ao determinado pela Resolução CNE/CEB n..$^{0}$ 2, de 10 de maio de 2016, quando, por exemplo, na mesma se exige a contratação, para os quadros das escolas de educação básica, de professores licenciados em Música -, como tal facto reforça a ideia de que, no conflito conceptual entre uma Educação Artística integradora, como a conceptualmente prevista pela $L D B$ de 1971, e uma concepção curricular de Arte mais desagregada, como a prevista pela atual redação dada aos $\S \S 2 .^{\circ}$ e $6 .^{0}$ do artigo 26. ${ }^{\circ}$ da $L D B E N$ de 1996 , estaremos a viver um retrocesso com claros riscos de se repetir, no âmbito curricular de Arte, o domínio hegemônico de uma das quatro linguagens artísticas hoje expressamente previstas no já mencionado $\S 6 .^{\circ}$ do artigo $26 .^{\circ}$ da $L D B E N$ de 1996 , mesmo que

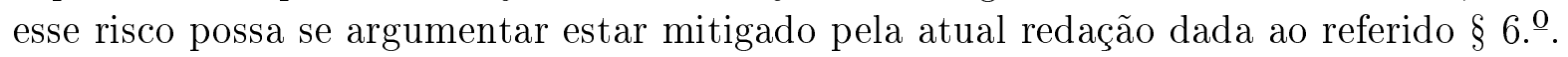

Vamos agora analisar a situação das artes nas escolas de ensino fundamental da rede municipal de Palmas, Tocantins, nos anos escolares de 2017 e 2018, realidade esta que não podendo ser diretamente extrapolada para o restante do Estado do Tocantins, pode não deixar de ser um microcosmo de uma tendência mais vasta. Neste sentido, podemos começar por referir que no

\footnotetext{
${ }^{29}$ É curioso de notar que a redação dada a esta observação faz referência à Lei n. ${ }^{0} 11.769$, de 11 de agosto de 2008, quando a mesma foi ultrapassada, na redação dada ao $\S 6 .^{\circ}$ do artigo $26 .^{\circ}$ da $L D B E N$ de 1996 , pela Lei n..$^{0} 13.278$, de 2 de maio de 2016, o que torna tal referência extemporânea na forma como a mesma é efetuada (note-se que a Resolução em causa é de dezembro de 2016).
} 
Tab. 3: Professores concursados com a função de professor de música na Prefeitura Municipal de Palmas durante o segundo semestre de 2017.

\begin{tabular}{|c|c|c|c|c|}
\hline \multirow{2}{*}{ Cargo } & \multicolumn{3}{|c|}{ Formação } & \multirow{2}{*}{ Totais } \\
\cline { 2 - 5 } & Magistério (Nivel Médio) & Pedagogia (Licenciatura) & Educação Musical (Licenciatura) & \\
\hline \hline $\mathbf{P}-\mathbf{I}$ & 9 & 1 & 1 & $\mathbf{1 1}$ \\
\hline $\mathbf{P}-\mathbf{I I}$ & 1 & 3 & 1 & $\mathbf{5}$ \\
\hline
\end{tabular}

período considerado (anos escolares de 2017 e 2018), somente as escolas de ensino fundamental da referida Prefeitura, a funcionarem em regime de Tempo Integral, possuíam no seu currículo as disciplinas de Música (Educação Musical), Dança e Teatro, no âmbito da parte diversificada do currículo e no que às artes diz respeito, ${ }^{30}$ isto apesar de haver projetos musicais relevantes em escolas de Tempo Parcial. ${ }^{31}$ No que à música especificamente diz respeito, algumas escolas tinham projetos musicais específicos, nomeadamente a Orquestra Sanfônica da Escola Municipal Beatriz Rodrigues, a Orquestra de Cordas da Escola Municipal de Tempo Integral Monsenhor Pedro Pereira Piagem, e o Projeto Vereda da Escola Municipal Crispim Pereira Alencar, em Taquaruçu, este último visando, entre outros, a preservação e prática da Viola de Buriti.

Paralelamente a estes projetos musicais em curso em algumas das escolas da referida rede municipal, havia ainda outros projetos de âmbito musical, como foi o caso da Cantata de Natal, que implicaram a participação de diversas escolas da referida rede, tendo, apesar disso, como seu suporte o projeto do Coral da Escola Municipal de Tempo Integral Padre Josimo, da responsabilidade de um dos dois professores concursados, na referida rede municipal, licenciados em Música. Complementarmente, a Prefeitura Municipal de Palmas realizou, em 2017 e em 2018, um Festival de Artes das Escolas de Palmas (FAES), promovendo, desta forma, diversas apresentações artísticas em cada uma das quatro linguagens previstas na atual redação do $\S 6 .{ }^{0}$ do artigo 26. ํㅡㄹ da $L D B E N$ de 1996 (artes visuais, dança, música e teatro). No entanto, toda esta prática artística funcionou mais numa lógica de criar um produto visando a sua apresentação pública, do que numa perspectiva estrita e eminentemente pedagógica, não havendo espaço para um suporte que permitisse uma concepção curricular, teoricamente sustentada, no que à inclusão destas linguagens artísticas no currículo destas escolas diz respeito. De facto, ao nível da própria Secretaria Municipal de Educação, a Diretoria de Belas Artes, redenominada em 2018 de Diretoria de Projetos Especiais, se ocupava somente da produção das apresentações públicas de carácter artístico, não tendo um papel de efetiva direção pedagógica das componentes curriculares previstas no currículo de Arte destas escolas municipais.

Uma outra questão interessante a analisar diz respeito à formação dos professores de Arte $^{32}$ da referida rede, em especial no âmbito da música. ${ }^{33}$ Apesar da qualidade da informação disponível poder ser pontualmente questionável, segundo os recursos humanos da referida Prefeitura, no segundo semestre de 2017, de um total de 16 professores efetivos lecionando Música

\footnotetext{
${ }^{30}$ Paralelamente a estas, encontra-se prevista uma disciplina de Arte no âmbito da área de conhecimento das linguagens, a qual aborda tendencialmente, na prática que eu pude presenciar, conteúdos relacionados com as artes visuais.

${ }^{31}$ Este era, por exemplo, o caso da Orquestra Sanfônica sediada na Escola Municipal Beatriz Rodrigues.

32 Dado existirem poucos professores habilitados com o grau de licenciatura em Música no Tocantins, e visto a forma como estes professores têm vindo a ser contratados na área das artes, não nos é possível desligar uma análise dos professores afetos à lecionação da educação musical dos professores afetos à lecionação das restantes linguagens artísticas, até porque o mesmo professor de Arte tende a ter a seu cargo, pelo menos teoricamente, a lecionação de mais do que uma destas linguagens artísticas, entre as quais, a música.

33 Podemos adiantar que a música parece ser a este nível uma excepção no caso geral das artes, isto porque, ao nível dos referidos professores concursados, dos nove professores de Teatro, sete tinham licenciatura em Artes Cênicas, e dos três de dança, um tinha licenciatura em Educação Física e um outro tinha licenciatura em Dança.
} 
nas escolas da referida rede municipal, somente dois possuíam uma licenciatura em Música, havendo outros quatro professores que eram licenciados em Pedagogia (ver Tabela 3 na página precedente). De facto, estes números são genericamente coincidentes com outros indicadores então recolhidos, no caso em apreço, através de um questionário efetuado aos professores de Música da referida rede escolar: de um total de dez questionários respondidos e validados incluindo agora também professores contratados ou vinculados a projetos musicais no âmbito da rede municipal de ensino a um qualquer título, como seja o programa Mais Educaçã $o^{34}{ }_{-}$, três estavam cursando, e um outro já tinha concluído, a licenciatura em Música.

Quanto às aulas de Música propriamente ditas, somente um, dos oito professores que referem estar lecionando a referida disciplina, ${ }^{35}$ quando questionados sobre o tipo de conteúdos/atividades musicais que desenvolvem com seus alunos, menciona prosseguir um modelo de ensino/aprendizagem informado ao nível de um construto teórico no âmbito da pedagogia musical moderna, fazendo expressa menção ao modelo $\mathrm{C}(\mathrm{L}) \mathrm{A}(\mathrm{S}) \mathrm{P}^{36}$ de Keith Swanwick. Todos os restantes sete professores não apresentaram, nas suas respostas a esta questão, um qualquer modelo teórico similar ${ }^{37}$ como orientador das suas práticas pedagógicas nas referidas aulas de Música, o que pode demonstrar um estado ainda precário na implementação de uma educação musical na referida rede escolar.

\section{Considerações Finais}

Chegados a este ponto, há já algumas ideias que podemos sistematizar quanto ao estado da educação musical no Tocantins tendo por base uma breve análise às estruturas curriculares das escolas estaduais desde 2012 até os dias de hoje, bem como quanto à realidade vivenciada nas escolas da rede municipal de Palmas, Tocantins, partindo ainda de um enquadramento mais vasto e de aplicação nacional. De facto:

1. Podendo-se vislumbrar um conflito conceptual latente entre dois modelos de Educação Artística - um mais integrador das diversas linguagens artísticas ( $L D B$ de 1971) e um outro que propõe uma maior autonomia entre essas mesmas linguagens ( $L D B E N$ de 1996) -, a $B N C C$ [28], no que diz respeito à Arte, pode ser parcialmente entendida como sendo um retorno ao conceito de Educação Artística subjacente à $L D B$ de 1971 e em sentido contrário à evolução havida na redação dada aos $\S \S 2 .^{\circ}$ e $6 .^{\circ}$ do $\operatorname{artigo} 26 .^{\circ}$ da $L D B E N$ de 1996 em um pouco mais de uma década de sua existência;

2. Esse mesmo conflito conceptual pode ainda ser eventualmente aferido das alterações ocorridas nas estruturas curriculares das escolas estaduais no que ao ensino fundamental diz respeito, nomeadamente dado o desaparecimento da disciplina de Educação Musical das respetivas estruturas curriculares a partir do ano escolar de 2017;

3. A inobservância generalizada de determinações constantes da Resolução CNE/CEB n. ${ }^{0}$ 2, de 10 de maio de 2016, havendo mesmo um aparente desconhecimento quanto à sua existência, isto apesar de a mesma estabelecer obrigações muito precisas e relativas à

\footnotetext{
${ }^{34}$ Dos dez questionários respondidos e validados, cinco se referem a professores efetivos da referida rede, três ao Mais Educação, um a professor contratado e um outro a estagiário.

35 Os outros dois estavam afetos a projetos musicais mas não às aulas de música propriamente ditas.

36 Por vezes traduzido para português como $\mathrm{T}(\mathrm{E}) \mathrm{C}(\mathrm{L}) \mathrm{A}$.

37 Isto não significa que estes sete professores não tenham algum modelo teórico subjacente às suas atividades de ensino/aprendizagem. Por exemplo, entre as respostas dadas temos "[o] conhecimento básico do instrumento violão [...] nomes das notas, o que é [a] escala cromática, campo harmônico" ou "[a] teoria das notas musicais, [as] músicas seculares, [a] interpretação de letras de músicas, [o] canto direcionado e espontâneo, dentre outros." Contudo, é difícil ver, nestas respostas, alguma corrente da pedagogia musical moderna.
} 
implementação de uma educação musical de qualidade ${ }^{38}$ em toda a educação básica brasileira;

4. A extrema precaridade na qual a educação musical tem existido, quer derivado a uma deficiente formação dos respetivos professores que não possuem o necessário grau de licenciado na área, quer por uma estrutura a que lhe falta um claro construto teórico no âmbito da pedagogia musical moderna, isto para já não nos referirmos ao facto de que a música nem sempre tem estado presente nas respetivas estruturas curriculares, remetendo-nos a um modelo de Educação Artística que no passado levou à hegemonização das artes visuais em detrimento de outras linguagens artísticas como a música, e que terá motivado a atual redação do já mencionado $§ 6 \cdot^{0}$ do artigo $26 .^{0}$ da $L D B E N$ de 1996.

Sendo este um estudo com óbvias limitações, o mesmo não nos deixa, no entanto, de apontar algumas pistas para um possível futuro que dê efetivo cumprimento à prática de uma educação artística de qualidade, na qual a música não pode ser uma parte menor - a par das artes visuais, do teatro e da dança -, e que deverá estar inserida num currículo devidamente informado pelo que há de mais recente ao nível da pedagogia musical. Ou seja, há que se construir um currículo de música cientificamente válido e validado em vez de o mesmo ser um mero amontoado de ideias, por vezes desconexas e desfocadas do que é fazer e aprender música em pleno século XXI.

E não deixa de ser relevante constatar as profundas diversidades entre os discursos e as práticas vigentes quando se comparam realidades nacionais distintas, como por exemplo, a existência de um sistema de ensino artístico especializado ao nível da educação básica (inexistente no Brasil), ou quando os discursos pedagógicos que justificam a inclusão da música no currículo escolar são embasados na constatação empírica de que os alunos com melhor aproveitamento acadêmico são exatamente aqueles que também estão envolvidos em práticas de ensino/aprendizagem musical, tal como acontece nos Estados Unidos. Há, pois, que conhecer essa mesma diversidade, procurando pensar a problemática da educação musical numa perspectiva mais ampla e vasta, integrando conhecimentos e práticas diversos, advindos de outras realidades e formas de pensar.

\section{Referências}

[1] Brito, T. A de (2001). Koellreutter educador: O humano como objetivo da educação musical. São Paulo: Peirópolis.

[2] Broh, B. A. (2002). Linking extracurricular programming to academic achievement: Who benefits and why? Sociology of Education, 75(1), 69-95.

[3] Bueno, P. \& Bueno, R. (2009). Uma proposta metodológica para se ensinar música musicalmente. Anais do IX EDUCERE, Curitiba, PR, Brasil, 8430-8440. Recuperado de http://educere.bruc.com.br/arquivo/pdf2009/3568_2012.pdf

[4] Decreto-lei n. 344/90, de 2 de novembro de 1990. Estabelece as bases gerais de organização da educação artística pré-escolar, escolar e extraescolar. Recuperado de https://dre.pt/web/guest/pesquisa/-/search/566188/details/normal?q= Decreto-lei+n.ž\% $20344 \% 2 \mathrm{~F} 1990$

\footnotetext{
38 Essa exigência de qualidade pode ser aferida pela obrigação estabelecida no sentido de se realizarem concursos específicos para a contratação de licenciados em Música no âmbito das Secretarias Municipais e Estaduais de Educação [32, art. 1. $.^{\circ}, \S 2 . \stackrel{0}{ }$, VII].
} 


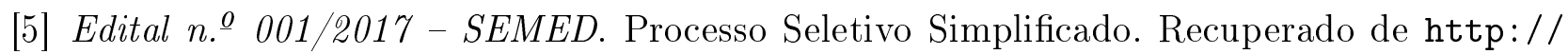
diariooficial.palmas.to.gov.br/media/diario/1907-28-12-2017-18-39-23.pdf

[6] Fernandes, D., Ramos do Ó, J. \& Boto Ferreira, M. (2007). Estudo de avaliação do ensino artístico: Relatório final revisto. Recuperado de https://www.researchgate.net/ publication/314216737_Estudo_de_Avaliacao_do_Ensino_Artistico

[7] Fernandes, D., Ramos do Ó, J. \& Paz, A. (2008). Ensino artístico especializado da música: Para a definição de um currículo do ensino básico. Recuperado de https://www.researchgate.net/publication/314216745_Ensino_Artistico_ Especializado_da_Musica_Para_A_Definicao_De_Um_Curriculo_Do_Ensino_Basico

[8] Gardner, H. (1995). Inteligências múltiplas: A teoria na prática. Porto Alegre: Artes Médicas.

[9] Giannattasio, G. \& Ivano, R. (Org.). (2011). Epistemologias da história: Verdade, linguagem, interpretação e sentido na pós-modernidade. Londrina: EDUEL.

[10] Gomes, C. (2000). Contributos para o ensino especializado de música em Portugal (Memória Final). Escola Superior de Educação de Almada do Instituto Jean Piaget, Almada, Portugal. Recuperado de https ://www.academia.edu/40439643/Memoria_Final

[11] Gomes, C. (2002). Discursos sobre a «especificidade» do ensino artístico: A sua representação histórica nos séculos XIX e XX (Tese de Mestrado). Faculdade de Psicologia e de Ciências da Educação da Universidade de Lisboa, Lisboa, Portugal. Recuperado de http://hdl.handle.net/10451/34811

[12] Gordon, E. (1993). A music learning theory. Chicago: GIA Publications.

[13] Gordon, E. (1998). Introduction to research and the psychology of music. Chicago: GIA Publications.

[14] Gordon, E. (2000a). Teoria da aprendizagem musical: Competências, conteúdos e padrões. Lisboa: Fundação Calouste Gulbenkian.

[15] Gordon, E. (2000b). Teoria da aprendizagem musical para recém-nascidos e crianças em idade pré-escolar. Lisboa: Fundação Calouste Gulbenkian.

[16] Hodges, D. A. \& O'Connell, D. S. (2005). The Impact of Music Education on Academic Achievement. In M. Luehrsen (Ed.), Sounds of Learning: the Impact of Music Education (pp. 2.1-2.33). Carlsbad, CA: International Foundation for Music Research.

[17] Lei n. 11.769, de 18 de agosto de 2008. Altera a Lei no 9.394, de 20 de dezembro de 1996, Lei de Diretrizes e Bases da Educação, para dispor sobre a obrigatoriedade do ensino da música na educação básica. Recuperado de http://www.planalto.gov.br/ccivil_03/ _Ato2007-2010/2008/Lei/L11769.htm

[18] Lei n. ${ }^{\circ}$ 12.796, de 4 de abril de 2013. Altera a Lei n. ${ }^{0}$ 9.394, de 20 de dezembro de 1996, que estabelece as diretrizes e bases da educação nacional, para dispor sobre a formação dos profissionais da educação e dar outras providências. Recuperado de http: //www.planalto.gov.br/CCIVIL_03/_Ato2011-2014/2013/Lei/L12796.htm

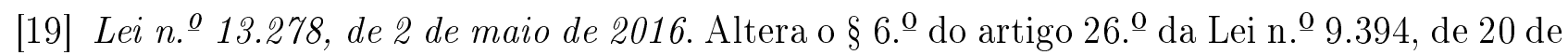
dezembro de 1996, que fixa as diretrizes e bases da educação nacional, referente ao ensino da arte. Recuperado de http://www.planalto.gov.br/ccivil_03/_ato2015-2018/2016/ lei/113278.htm 
[20] Lei n. ${ }^{0}$ 13.415, de 16 de fevereiro de 201\%. Altera as Leis n. ${ }^{\circ} \mathrm{S} 9.394$, de 20 de dezembro de 1996, que estabelece as diretrizes e bases da educação nacional, e 11.494, de 20 de junho 2007, que regulamenta o Fundo de Manutenção e Desenvolvimento da Educação Básica e de Valorização dos Profissionais da Educação, a Consolidação das Leis do Trabalho - CLT, aprovada pelo Decreto-Lei n. ${ }^{0} 5.452$, de $1 .^{0}$ de maio de 1943 , e o Decreto-Lei n. ${ }^{0} 236$, de 28 de fevereiro de 1967; revoga a Lei n. ${ }^{0} 11.161$, de 5 de agosto de 2005; e institui a Política de Fomento à Implementação de Escolas de Ensino Médio em Tempo Integral. Recuperado de http://www.planalto.gov.br/ccivil_03/_ato2015-2018/2017/lei/113415.htm

[21] Lei n..$^{0}$ 46/86, de 14 de outubro. Lei de Bases do Sistema Educativo (versão consolidada). Recuperado de https://dre.pt/web/guest/legislacao-consolidada/-/lc/ $34444975 /$ view?p_p_state $=$ maximized

[22] Lei n..$^{0}$ 5.692, de 11 de agosto de 1971. Fixa diretrizes e bases para o ensino do 1. ${ }^{\circ}$ e 2..$^{\circ}$ graus e dá outras providências. Recuperado de http://www.planalto.gov.br/ccivil_ 03/LEIS/L5692.htm

[23] Lei n.o 85/2009, de 27 de agosto. Estabelece o regime de escolaridade obrigatória para as crianças e jovens que se encontram em idade escolar e consagra a universalidade da educação pré-escolar para as crianças a partir dos 5 anos de idade. Recuperado de https: //data.dre.pt/eli/lei/85/2009/08/27/p/dre/pt/html

[24] Lei n. .9 .394 , de 20 de dezembro de 1996. Estabelece as diretrizes e bases da educação nacional. Recuperado de http://www.planalto.gov.br/ccivil_03/LEIS/L9394.htm

[25] Leite, G. \& Cruz, R. L. P. (2018, 19 abr.). Sobre a hierarquia das leis no direito brasileiro. Jornal JURID. Disponível em https://www.jornaljurid.com.br/colunas/ gisele-leite/sobre-a-hierarquia-das-leis-no-direito-brasileiro

[26] Medida Provisória n. 746 , de 22 de setembro de 2016. Institui a Política de Fomento à Implementação de Escolas de Ensino Médio em Tempo Integral, altera a Lei n ${ }^{0}$ 9.394, de 20 de dezembro de 1996, que estabelece as diretrizes e bases da educação nacional, e a Lei n o 11.494 de 20 de junho 2007, que regulamenta o Fundo de Manutenção e Desenvolvimento da Educação Básica e de Valorização dos Profissionais da Educação, e dá outras providências. Recuperado de http://www.planalto.gov.br/ccivil_03/_Ato2015-2018/2016/ $\mathrm{Mpv} / \mathrm{mpv} 746 . \mathrm{htm}$

[27] Mateiro, T. \& Ilari, B. (Org.) (2012). Pedagogias em Educação Musical. Curitiba: InterSaberes.

[28] Ministério da Educação (2018). Base Nacional Comum Curricular: Educação é a Base. Brasília: Autor. Recuperado de http://basenacionalcomum.mec.gov.br/images/BNCC_ EI_EF_110518_versaofinal_site.pdf

[29] Portaria GAB/SEMED n. ${ }^{o}$ 16, de 16 de janeiro de 2019. O Sistema Integrado de Análise Curricular - SIAC-SEMED, destinado a selecionar candidatos para o preenchimento do quadro de servidores do magistério na forma de contratações temporárias. Recuperado de http://diariooficial.palmas.to.gov.br/media/diario/ 2162-16-1-2019-20-30-9.pdf

[30] Resolução CEE/TO n.ำ 11, de 14 de fevereiro de 201\%. Aprova e dá outras providências as Estruturas Curriculares da Rede Estadual de Ensino. Recuperada de https://central3. to.gov.br/arquivo/343072/ 
[31] Resolução CEE/TO n..$^{0}$ 160, de 19 de dezembro de 2016. Aprova as estruturas curriculares da Rede Estadual de Ensino. Recuperada de https://central3.to.gov.br/arquivo/ 343073/

[32] Resolução CNE/CEB n.o 2, de 10 de maio de 2016. Define diretrizes nacionais para a operacionalização do ensino de música na educação básica. Recuperado de http://pesquisa.in.gov.br/imprensa/jsp/visualiza/index.jsp?jornal= $1 \&$ data $=11 / 05 / 2016$ \&pagina $=42$

[33] Ribeiro, A. \& Vieira, M. ${ }^{\text {a }}$ (2016). A articulação entre o ensino especializado da música e o sistema geral de ensino em Portugal: Impacto atual da reestruturação de 2009. Opus, 22(1), 237-254. Recuperado de https : / /ww . anppom.com.br/revista/index.php/opus/ article/view/353/357

[34] Rodrigues, H. (2002). Avaliação da aptidão musical: Viagem em torno de questões históricas e epistemológicas rumo a uma reflexão sobre a actualidade. Revista Portuguesa de Musicologia, 12, 181-210. Recuperado de http://rpm-ns.pt/index.php/rpm/article/ download/130/132

[35] Russel, B. (1957). História da Filosofia Ocidental. São Paulo: Companhia Editora Nacional.

[36] Secretaria da Educação e Cultura. (2009). Referencial Curricular: Ensino Fundamental 1. ao 9. ano. Palmas, TO: Autor. Recuperado de https://pt.slideshare.net/ denisealvesf/referencial-curricular-ensino-fundamental-2009-tocantins

[37] Secretaria da Educação, Juventude e Esporte. (2012). Estruturas Curriculares da Rede Estadual de Ensino do Tocantins: Ensino Fundamental. Recuperado de https://seduc. to.gov.br/gestao/legislacao-e-normas/estruturas-curriculares/

[38] Secretaria da Educação, Juventude e Esporte. (2014). Estruturas Curriculares da Rede Estadual de Ensino do Tocantins: Ensino Médio. Recuperado de https://seduc.to.gov . $\mathrm{br/gestao/legislacao-e-normas/estruturas-curriculares/}$

[39] Secretaria da Educação, Juventude e Esporte. (2017). Estruturas Curriculares da Rede Estadual de Ensino do Tocantins. Recuperado de https://seduc.to.gov.br/gestao/ legislacao-e-normas/estruturas-curriculares/

[40] Swanwick, K. (1988). Music, Mind and Education. London: Routledge. 